\title{
Electromagnetic Interference
}

National Cancer Institute

\section{Source}

National Cancer Institute. Electromagnetic Interference. NCI Thesaurus. Code C63214.

Problem associated with a measure of electromagnetic radiation from equipment. 